\title{
Design Research on the Display of Revolution Museum
}

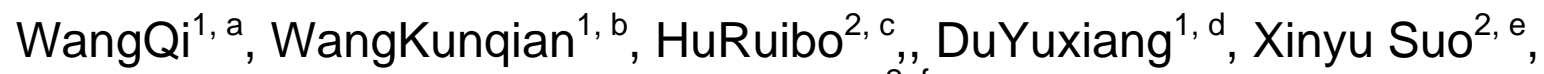 \\ RenPing $X u^{2, f}$ \\ ${ }^{1}$ Kunming University of Science and Technology, Kunming, P.R.China \\ ${ }^{2}$ Guizhou Normal University ,Guiyang, P.R.China \\ '625404977@qq.com, wangkunqian04@sina.com, ${ }^{\mathrm{a} m y s j g z s @ 126 . c o m, ~}{ }^{\mathrm{d}} 407904118 @ q q . c o m$
}

Keywords: revolutionary memorial, exhibition design, innovation, memorial hall of Yunnan anti-Japanese war victory

\begin{abstract}
Museum display design is a display art, which needs to compose a visual display form with strong series of art image in a certain space environment, making the audience accept the exhibition information in the process of flow in a reasonable and effective way. This thesis analyzes the design theme of revolution museum display, discussing the necessity of design innovation for revolutionary memorial hall, gets the innovation principle of display design for revolutionary memorial hall, designs case for the underground gallery of Yunnan anti-Japanese victory memorial hall, and verifies the rationality and feasibility of innovative design principle of the display of revolutionary memorial hall.
\end{abstract}

\section{Introduction}

Since the 30 years of reform and opening up, a larger number of Chinese museums, memorials spring up like mushrooms. However, as the development information transmission technology and methods, audiences require more for the design and function of museums. For designers of museums, how to use innovative concepts to guide the design and art practice of Chinese memorial museums' displaying becomes an important topic. For the ascension and modification work of memorial hall for Yunnan anti-Japanese war victory, innovative concepts must be used to guide the practice of History of Yunnan Revolution's display and design art.

\section{Topicality of Revolutionary Memorial Hall's display and design}

Harmony. Harmony means that the whole exhibition rhythm should be grasped, and the main line of outline should be taken as instruction, to highlight the key historical events of each period, thus achieving the overall coordination of points, lines, and sides, penetrating them into a general rhythm, which can be in a degree of relaxation, one climax after another and coherent.

Atmosphere. No matter from the aspect of grasping colors or from the aspect of displaying forms, the art and aesthetic of the whole exhibition should be considered. It is not a simple adornment or a form composition isolated from exhibit and audience, but it should be with higher taste, being able to foil the product connotation and give audiences a kind of aesthetic enjoyment.

Pace. That is to strengthen the rhythm organization of forms. The dynamic line of exhibition hall should include planner of exhibition outline and things that designers expect audiences to know mainly, and have overall rhythm layout of methods such as plain shape and solid shape of display forms, vision and auditory, sense of touch, combining the needs of content, to strengthen attraction, infection and shocking, making audiences always have feeling of freshness instead of being tried in the process of visit. History knowledge is expected to be remembered in an atmosphere of edutainment.

In the creation of Yunnan Revolution History's display and design case in Yunnan anti-Japanese war victory memorial hall, what should be considered first is that it should not be a common decoration design, but a design reflecting the bright political theme of revolutionary memorial and abundant and tortuous connotation. The design should display the revolutionary theme of Yunnan 
anti-Japanese war victory in the form of art. The exhibition's design target should be positioned as establishing a representative patriotism education base and red tourist attraction and exhibitions after reformation and promotion should not lag behind for 10 years to 20 years. After the theme is determined, according to the above three design concepts, the first step is to deal with the internal overall and grand design of exhibition hall harmoniously. For example, in the processing of exhibition line, I follow the clockwise direction which shows a clear visit order, the route being not crossed, not countercurrent, guaranteed strong consistency of exhibition content, being distinct and easy to argue, making the audience feel just like being in the situation and recall the passing history according to the progress of events.

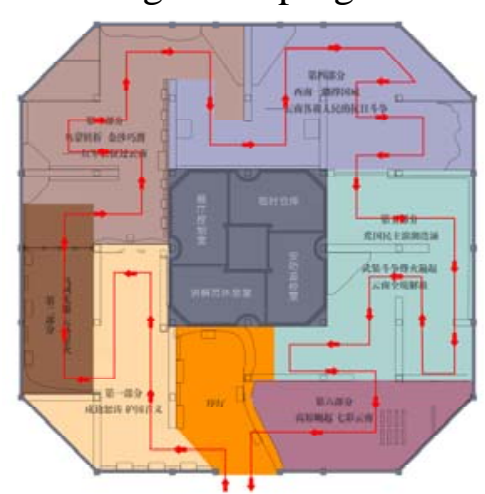

Fig. 1 Audience flow diagram

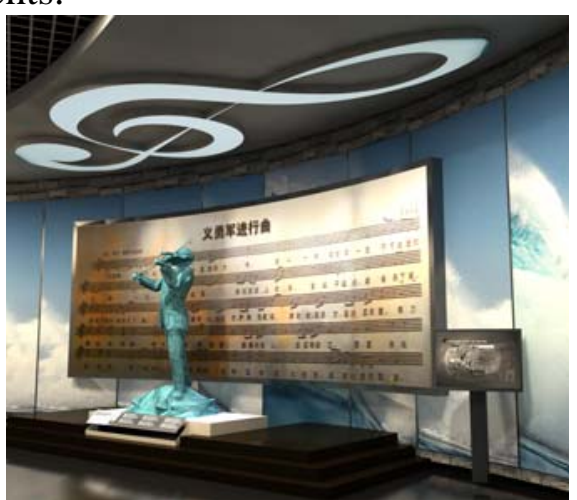

Fig. 2 Nie er grief wall

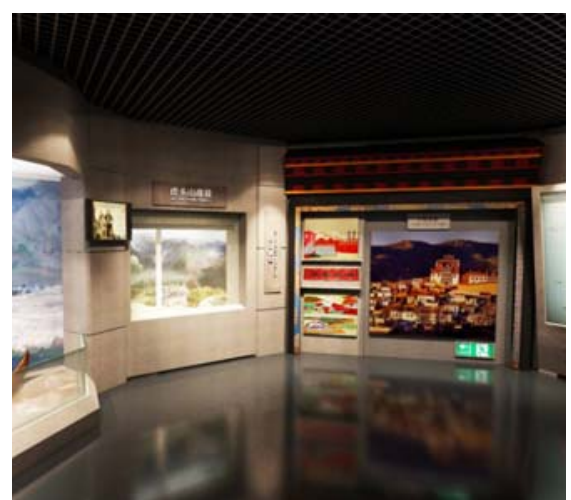

Fig3. King Semi Painting

Next, content of each chapter in the outline will be researched further to determine the design methods of forms for each exhibition hall's atmosphere creation. The exhibition content text is the premise and basis of museum's exhibition form design while the thoughts and content of exhibition must be expressed through a certain form because only through perfect art form, can the content of exhibition be expressed accurately, vividly and distinctively. For example, the theme of the second part is "Marxist-Leninism pioneer playing the role of sparks", reflecting that the new culture movement and the May 4th movement promoted the spread of Marxism in Yunnan, lit the frame of Yunnan people's revolutionary struggling spirit. Moreover, one part wall has been made into the form of mimeograph newspaper, making audience feel that they are just like living in those years of passion burning, and multimedia image virtual time-space scenario has been coupled, strengthening the interaction and communication of three dimensions.

Finally, the exhibition rhythm should be grasped and the pace of audience should be controlled. Display is to convey information to people, whose design must relate to people's psychological feelings and reactions. In the process of exhibition, large amount of feelings, perception, attention, memory and some other things in psychology has been applied to consider the designs of pictures, characters, colors and some other aspects in the exhibition. For example, the forth part is "The southwest corner braces countries crisis - the anti-Japanese war of Yunnan ethnic groups”, based on the fact that Yunnan people actively participated in the theme of anti-Japanese war, different from the former exhibitions of heavy colors, colors changing occasionally but not breaking dignified atmosphere, which not only reflects Yunnan people's determination and will to fight and also adjusts the aesthetic experience of audiences from the mental perception.

\section{King Semi Painting}

Intelligent multimedia interactive sandbox navigation systerm of sound, light and electricity. The intelligent multimedia interactive sandbox navigation system of sound, light and electricity is based on the combination of "three-dimensional sand table model scene" and "sound, light, electricity, smoke, rain, fig and projection”, projecting those pictured and made videos onto the big screen near the three-dimensional sand table model scene, to demonstrate regaining, segmenting and fighting process.

Sound, light, electricity, smoke, fog and projection. "Sound, light, electricity, fog and projection" are combined with each other to demonstrate the detonation instant process of 
Matsuyama main peak. Moreover, there are simulated bombing sound and burning effects, coupled with realistic high-fidelity surround sound.

Phantom imaging system. The phantom image system combines the real shapes and virtual images together, particularly suitable for use. For the reproduction of scene and scenarios, the Surprise Attack of Mengzi Airport in Diannan Battle can be recovered, projecting virtual images onto this scene, to reproduce history. Through the application of the above sound, light and electricity technology, and combined with the regional characteristics of Yunnan, making the audience to acquire information in the process of participation and cooperation. A bundle of device modeling and image conversion has constructed ever-changing audio-visual spatial forms, making time and spaces have an instant re-interpretation, taking people into a dreamlike scenario, fully demonstrating history of Yunnan revolutionary struggle and Yunnan people's indomitable spirit, and truly reflecting roles and significance of modern shows.

\section{The innovation principle of revolutionary memorial hall's display and design}

Empirical. The enhancement and transformation work of "Yunnan Revolutionary Struggle History" must be based on the original work to use a large number of hominid card, evidence, documentary evidence, pictures, audio and video, historical archives and some other things, in order to strengthen the exhibition effects. The nearly 1500 square meters of exhibition areas are only used to exhibit the original 274 pieces of photographs data, historical data, historical documents and revolutionary relics, which appearing thin content. Only by empirical artifacts and information, can the majority of audience truly achieve enlightenment and education.

Functional. The exhibition design of a museum, no matter which aesthetic theory it derives from, or which means it takes, has to comply with all the functional requirements of museum, a particular place, essentially. Moreover, it must serve the heritage and audience itself and the requirements of heritage inside the hall and audience have to be considered.

Regional. The exhibition of "Yunnan History Revolutionary Struggle" mush be prominent its geographical features, and what need to be demonstrated is the revolutionary struggle of Yunnan history. In the historical context of national revolutionary, the characteristics of Yunnan should be emphasized.

Technological. Properly combination of display content and high-tech multimedia tools can reproduce history vividly, strength audience's visit interest and deepen their memory, which also reveals the advance of modern memorial. Electronic pages-it uses modern light sensor infrared technology. Therefore, the audience just needs to wave their hands above e-books, which can achieve real-time browse and query, making information achieve personalized transferring. The audiences are no longer the passive information acceptors, but the active seekers. The publicity is more targeted and the effect is more significant.

Interactive. On the other hand, the expressions of words and interpretation services should meet requirements from different regions, minorities, cultural levels, proceed from the exterior to the interior, and from one point to another, which makes the vast majority of audience can understand the exhibition during a visit; on the other hand, we should also establish various forms of academic communication space after complement of enhancement and transformation, paying attention to cooperation and academic between regions.

Humanity. On the one hand, it reflects the understanding for the visitors. Set proper rest areas in the visit hall, which can appropriately adjust our states of mind and relax our bodies. The cooperated demonstration of seating areas and interactive system, high-tech multimedia system, sound projection system and photo documentations can not only meet the requirements of audience to visit and study, but also it is convenient for family groups and different visit ages to have different rhythms of visit. On the other hand, in the design of exhibition, consider the memorial usage and the convenience of staff in the maintaining process from the replacement and maintaining of screen, lighting, and heritages.

Environmental conservation. The exhibition hall is located in the basement, which is a relatively closed environment. We should make fully use of environmental conservation materials 
of non-toxic and non-radiation. Moreover, in the design layout, some related facilities such as exhibition hall ventilation, emergency evacuation and fire.

Economical. The principle of the so-called economic refers to the economic accounting problems in the process of exhibition. We should strive to achieve the most suitable, high-quality and attractive design with the minimum cost. Therefore, we must begin the exhibition inputs early in the design process and a seminar of returning the audience "cost-effective".

\section{Conclusion}

In China, the revolutionary memorial hall takes history as subject, and depends on the text description, historical relics, files, images and some other elements to reproduce what happened at that time. Under this kind of serious topic, how should we make an innovation of exhibition design? The designers are required that they have to follow the necessary design principles, sort out the complicated elements and make appropriate choice under the premise of following the exhibition subject. Only through this, can backgrounds in different times be better introduced. In short, a good design can communicate and exchange with visitors, tell stories and cause the spiritual resonance.

\section{Reference}

[1] Ruibo Hu, Jingyuan Li, Liyan Chen, Renping Xu, Kunqian Wang, Xingran Mao. Application Study of Conceptual Design in the Product Design[J]. Applied Mechanics and Materials, 2012, Vols. 121-126: 730-734. (EI: 20114714533309)

[2] Ruibo Hu, Renping Xu, Kunqian Wang, Jingyuan Li. The Research of Virtual Tactile Design Application in Dongba Sculpture[J]. Advanced Materials Research, 2011, Vols. 228-229: 185-190. (EI: 20112113994664)

[3] Ruibo Hu, Renping Xu, Kunqian Wang, Xingran Mao. The Research of Developing and Constructing Tourist Attractions in Dong Jiahe[J]. Advanced Materials Research, 2011, Vols. 250-253: 3884-3888. (EI: 20112314040542) 